\title{
International Scientist Mobility and the Locus of Knowledge and Technology Transfer
}

\author{
Edler, Jakob; Fier, Hedie ; Grimpe, Christoph
}

\author{
Document Version \\ Accepted author manuscript \\ Published in: \\ Research Policy \\ DOI: \\ 10.1016/j.respol.2011.03.003 \\ Publication date: \\ 2011 \\ License \\ CC BY-NC-ND
}

Citation for published version (APA):

Edler, J., Fier, H., \& Grimpe, C. (2011). International Scientist Mobility and the Locus of Knowledge and

Technology Transfer. Research Policy, 40(6), 791-805. https://doi.org/10.1016/j.respol.2011.03.003

Link to publication in CBS Research Portal

\section{General rights}

Copyright and moral rights for the publications made accessible in the public portal are retained by the authors and/or other copyright owners and it is a condition of accessing publications that users recognise and abide by the legal requirements associated with these rights.

\section{Take down policy}

If you believe that this document breaches copyright please contact us (research.lib@cbs.dk) providing details, and we will remove access to the work immediately and investigate your claim.

Download date: 26. Apr. 2023

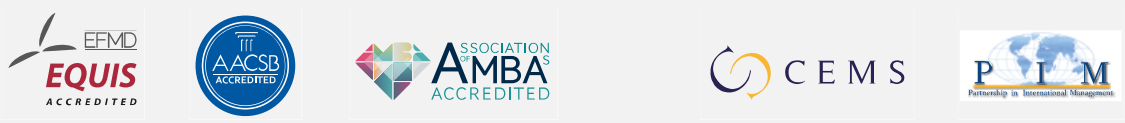




\section{International Scientist Mobility and the Locus of Knowledge and Technology Transfer}

\section{Christoph Grimpe, Jakob Edler, and Heide Fier}

Journal article (Post print version)

This article was originally published in Research Policy, Vol. 40, Issue 6, Pages 79180५. First published online: April २०, २०11

00l: 10.1016/j.respol.2011.03.003

Uploaded to Research@CBS: March २०16

(C) 2016. This manuscript version is made available under the CC-BY-NC-ND 4.0 license http://creativecommons.org/licenses/by-nc-nd/4.0/ 


\title{
International Scientist Mobility and the Locus of Knowledge and Technology Transfer
}

\author{
Jakob Edler \\ Manchester Institute of Innovation Research \\ MBS, University of Manchester, Harold Hankins Building, \\ Manchester, UK M13 9PL, Tel: (+44) (0) 161 275-0919 (-5921), jakob.edler@mbs.ac.uk \\ Heide Fier \\ Institute for Genomic Mathematics, University of Bonn \\ Sigmund-Freud-Str. 25, 53127 Bonn, Germany, heide.fier@uni-bonn.de \\ Christoph Grimpe \\ Copenhagen Business School, Dept. Innovation and Organizational Economics (INO) \\ Kilevej 14A, 2000 Frederiksberg, Denmark, Tel: (+45) 3815 2530, christoph@cbs.dk
}

Published in Research Policy, Vol. 40, 791-805. The final version can be found at http://www.sciencedirect.com/science/article/pii/S0048733311000382

\begin{abstract}
Despite the growing interest of scholars and policymakers to better understand the determinants for researchers in public science to transfer knowledge and technology to firms, little is known how temporary international mobility of scientists affects both their propensity to engage in knowledge and technology transfer (KTT) as well as the locus of such transfer. Based on a sample of more than 950 German academics from science and engineering faculties, we investigate how the duration and the frequency of scientists' visits at research institutions outside their home country affect KTT activities. We find that most mobile scientists engage in KTT to firms both in the host and in their home country, suggesting that KTT activities to firms abroad do not substitute or crowd out, but complement KTT to firms in the home country. We further find that the longer research visits abroad are, the higher the likelihood that scientists engage in KTT to firms, again both in the host and the home country. However, the more frequently scientists visit institutions abroad, the more likely they are to engage in KTT to firms only in their home country. Our results therefore provide evidence for the benefits of "brain circulation". The article contributes to the growing strand of literature on scientist mobility and on the determinants of industry-science linkages at the individual level.
\end{abstract}

Keywords: scientist mobility, knowledge and technology transfer, internationalisation

JEL classification: J61, O33 


\section{$1 \quad$ Introduction}

It has almost become conventional wisdom that knowledge originating from universities and public research centres is a crucial constituent of technological change and economic growth (e.g., Jaffe, 1989; Adams, 1990; Mansfield, 1991; Salter and Martin, 2001). In fact, knowledge and technology transfer (KTT) from academia to industry has attracted considerable attention in the literature with a focus on the scientists involved, the research institutions, the agents in technology commercialisation (e.g. transfer offices), or on the modes of transfer, such as formal and informal KTT (e.g., Schmoch et al., 2000; Siegel and Phan, 2005; Link et al., 2007; Rothaermel et al., 2007). Yet, despite the growing interest of scholars and policymakers in science, technology and innovation (STI) policy to better understand the factors motivating scientists ${ }^{1}$ to transfer knowledge and technology to firms, little is known how temporary international mobility ${ }^{2}$ of these scientists affects both the propensity to engage in KTT as well as the locus of such transfer.

This question is important for at least two reasons. First, international mobility of researchers in public science has increasingly become an integral part of academic careers (Edler, 2007; Ackers and Gill, 2008; Cox and Verbeek, 2008), and understanding the effects that mobility has on collaboration with industry can be assumed to yield insights for policy making. Second, international scientist mobility is implicitly associated with a discourse on "brain drain", affecting the technological capabilities through an absence of skilled workers and thus eventually the competitiveness of the home countries of mobile scientists in academia (Adams, 1968; Mountford, 1997). Moreover, temporary mobility might lead to permanent migration of scientists. In this respect, policy makers in all countries - not only in developing or emerging economies - are concerned that research activities of mobile scientists result in KTT to firms predominantly in the host country, although the scientist's research was substantially funded by the home country (OECD, 2002, 2007; Nguyen, 2006). Despite the vivid discussion of potential negative effects of international scientist mobility on the scientist's home country, however, a more recent approach has coined the term "brain circulation" to put emphasis on the benefits for both home and host country from scientists' international mobility (Regets, 2007).

Hence, in this paper we aim at shedding light on the relationship between international scientist mobility and scientists' KTT activities by analysing the role of both the duration of a research visit outside the scientist's home country and the frequency of such visits. In a first step, we identify the factors that motivate scientists in academia to become internationally mobile. We define scientist mobility ${ }^{3}$ as research visits at a host institution outside the scientist's home country that take longer than one month. Shorter activities, which for

1 In the following, we will use the term "scientist" as short-hand for scientists employed at universities and other public research institutes and centres in the field of science and engineering.

2 Mobility, obviously, is a complex term. In this paper, we focus on inter-national yet intra-sectoral mobility, i.e. mobility within academia. Thus, we are not concerned with moves from public research into firms, but with cross-border moves of university scientists.

3 We use the more general term mobility in contrast to other authors like Ackers and Gill (2008) who use the terms mobility and migration synonymously. 
example would also include the attendance of international conferences, can be assumed to impact KTT activities differently than being embedded as a visiting researcher at a host institution. Moreover, we do not consider permanent moves to another country which imply that the scientist does not have an immediate intention to return to the home country. In a second step, we focus on the scientist's decision to engage in KTT and on the locus of such activities.

Our theoretical reasoning is guided by the scientific and technical human capital approach (e.g. Bozeman et al., 2001; Bozeman and Corley, 2004; Boardman, 2009; Ponomariov and Boardman, 2010). Scientific and technical human capital has been described as "the sum of an individual researcher's professional network ties, technical knowledge and skills, and resources broadly defined” (Bozeman et al., 2001: 636). Consequently, international mobility can be characterised as a way to augment the scientist's professional network and the resources available, thus increasing the scientist's scientific and technical human capital. We suggest in this paper that scientific and technical human capital plays a key role in the transmission of scientific knowledge from academia to industry as it influences the ability and inclination of individual scientists to engage in KTT activities.

The empirical part of our paper is based on a random sample of more than 950 public scientists in Germany. We estimate Heckman selection models to account for the fact that not all scientists have international research experience. The paper further explores how KTT activities to home and host country firms relate to each other, i.e. we investigate whether KTT to host country firms substitutes or crowds out KTT to firms in the home country, or whether the two are complementary and mutually reinforcing. In this respect, we contribute to the literature in a number of ways. For the first time, we provide a direct link between international mobility and the KTT activities of scientists. While the effects of permanent migration have been studied in more detail, little is known about temporary mobility. Insights on this can be assumed to sharpen our understanding of the determinants of scientists' engagement in KTT activities and to inform STI policy making. Moreover, our data on mobile and non-mobile scientists allow for an investigation of the factors that encourage or discourage scientists to become internationally mobile. From a theoretical perspective, we conceptualise mobility as a driver of scientific and technical human capital which has been frequently shown to impact on scientific productivity.

The paper is organised as follows. The next section gives a brief review of the literature on scientist mobility and KTT activities and links the two in order to specify our hypotheses. Section 3 provides an overview of our empirical methods, before section 4 will show the empirical results. The paper concludes by outlining the implications of our findings for science and technology policy and by identifying further research opportunities at the intersection of scientist mobility and KTT activities. 


\section{$2 \quad$ Literature background}

\subsection{Mobility of scientists}

The discourse on the causes and effects of mobility of academics and highly skilled workers has frequently been associated with concerns about a potential brain drain. As a consequence, mobility has been framed in a context of loss and possible negative effects. This discussion goes back at least to Adams (1968) and has been coined in the context of development policy, analysing the scale, scope and consequences of the movement of scientific and economic elites from developing and emerging countries to a richer nation (Adams, 1968; Mountford, 1997; for an overview see Nguyen, 2006). However, while the discourse has long been focused on developing countries, initially the brain drain discussion was led in the United Kingdom in the 1950s and 1960s, when a loss of highly skilled workers and scientists to the United States had become apparent (Cervantes and Guellec, 2002). In the 1990s, the economic consequences of scientist and highly skilled worker mobility came back on the agenda of OECD countries (Salt, 1997; OECD, 2002; Schiff, 2005; Hunter et al., 2009). Recognising the importance of a sufficient pool of scientists and highly skilled workers, even in advanced countries worries about brain drain have re-emerged and been counteracted by policy schemes to retain the scientific elites. Indeed, the phenomenon of scientist mobility has been discussed in most OECD countries as a potential risk to the economy of the sending country. ${ }^{4}$ For example, the United Kingdom and the United States have intensified their efforts to re-attract or retain scientific elites at the end of the 1990s and beginning of the 2000s (Cervantes and Guellec, 2002).

However, the risk discourse around international mobility of scientists has not prevented a strong increase of international scientist mobility (Casey et al., 2001; OECD, 2002). Part of this mobility is migration, i.e. the move to another country in order to stay there for an indefinite time, and part is temporary. Although European governments in particular have been worried about a potential brain drain to the United States, existing data show that actual migration, i.e. the emigration of scientists, is rather limited (Cervantes and Guellec, 2002; Robinson et al., 2007). In contrast, temporary mobility has become more important in recent years, as scientists - and particularly PhD students and Post-Docs - gain experience abroad to come back and exploit the knowledge gained in their home country. Thus, the term brain circulation was coined in order to signal the potential gain stemming from temporary mobility, as such circulation implies linkages between national science and innovation systems (Saxenian, 2002).

The overall allocation of benefits from scientist mobility is, however, not entirely clear. Several authors find that higher mobility in terms of brain circulation not only leads to a better career development of individual scientists, ${ }^{5}$ but also contributes to the overall production and exchange of knowledge and subsequently potentially increases welfare (e.g., Thorn and

4 For the developing countries - which are not within the scope of our paper - this is obvious, although some views in the 1990s have claimed that the benefit for the sending country might be higher than the costs, which is - at least - a highly contested conclusion (Fiani, 2003).

5 Cox and Verbeek (2008) have shown that the impact on scientists is not always and automatically positive. 
Holm-Nielsen, 2006; Edler, 2007; Cox and Verbeek, 2008. Freeman (2010) presents data on the mobility of scientists, highly skilled workers, students and graduates (see also de Grip et al., 2010), together with shifts in global talent production towards Asia. He argues that mobility creates benefits with respect to the speed and breadth of knowledge production as well as regarding the global transfer of knowledge. At the same time, these benefits are accompanied by challenges for advanced Western countries in their competition with emerging economies like China or India (Freeman, 2010).

Scientist mobility is therefore said to enrich careers, create networks, support a better international flow of knowledge, better job matches through global job search and greater ability of employers to find rare or unique skill sets (Regets, 2007). All this allegedly leads to some form of cognitive integration in scientific fields across borders, facilitating complementarities in knowledge production. Regets (2007), in compiling international country-level data on mobile scientists with a focus on the US, claims not only an overall net benefit for the global economy and the receiving (host) countries, but also for the sending country. For the host country, Regets (2007) suggests increased incentives for natives to seek higher skills leading to an increase in domestic economic returns to human capital investments, increased knowledge flows and collaboration as well as increased ties to foreign research institutions, export opportunities for technology, remittances, and other support from “diaspora networks". Interestingly, and most important for our concern in this paper, Regets (2007) envisions very similar effects for the sending countries, thus making a strong argument for circulation and bi-directional benefits. However, these largely positive net effects of mobility for the receiving countries are not unambiguously supported in the literature. Both Bekhradnia and Sastry (2005) and Ackers and Gill (2008) argue that a high level of inward mobility may lead to dependencies on foreign in-flow that is unstable and hard to sustain combined with the risk of mobile researchers returning to their home countries, "taking their skills with them” (HEFCE, 2006: 44).

While brain drain remains an issue on the political agenda of some countries, the recent discourse has been about circulation and the requirement to enable and foster short and medium term stays. A major rationale behind those circulation programmes has been the insight that becoming part of global networks and collaborating with other scientists abroad enhances the capabilities and productivity of mobile scientists (Edler, 2007; Defazio et al., 2009). Scientists realise a whole range of positive individual benefits, and by doing so they create positive net effects in the country in which they are originally based and to which they return or keep up linkages. Therefore, European countries have intensified efforts to govern brain circulation in order to increase their benefits from scientist mobility (e.g., Thorn and Holm-Nielsen, 2006). Moreover, the insights on the benefits of scientist mobility have led to a "mobility strategy for the European Research Area (ERA)" in which mobility - with a focus on circulation - is seen as a major pillar for the creation of a single European market in science. ${ }^{6} \mathrm{x}$

In sum, apparently the fear of brain drain in some OECD countries has made way for more hope for brain circulation and related economic benefits. One increasingly recognised issue is

\footnotetext{
${ }^{6}$ For a summary see COM (2005).
} 
the potential benefit for home countries of temporarily mobile scientists through an increased "knowledge flow across borders" (Regets, 2007). There is however a severe shortage of empirical knowledge about the modes, scale and scope of effects of circulation of public scientists for the innovation system of both receiving and sending countries. We do not know to what extent mobile scientists do engage in KTT and where they mainly do it, either in the receiving or the sending country. Moreover, we know little about the factors that determine why scientists engage in KTT and, equally important, what drives them to become internationally mobile in the first place. Our paper is intended to fill this specific gap. It does not claim to discuss the broader consequences of migration or mobility, but instead focuses on one specific aspect in-depth using a novel dataset. In the following section we will review the existing evidence on causes and effects of KTT activities from academia to industry, which subsequently will be linked with the discussion of scientist mobility in order to derive our hypotheses.

\subsection{Knowledge and technology transfer from academia to industry}

There is wide agreement today that collaboration between science and industry plays a crucial role for the innovative capabilities of firms as well as for the overall economic development of a country (e.g., Hall et al., 2003; Link and Scott, 2005). With the rise of the "mode 2 concept" (Gibbons et al., 1994) which posits a close interaction between scientific and industrial actors in the production of knowledge, KTT activities between academia and industry have gained further importance. Minbaeva et al. (2003) define knowledge transfer as a multi-stage process which involves the identification of relevant knowledge, the actual transfer of knowledge, as well as its final use by the receiving organisational unit. However, since the subject of knowledge transfer cuts across a variety of academic fields and application contexts, there is no common definition of the term across the disciplines, and the definition depends on how knowledge itself is defined (Bozeman, 2000; Cummings and Teng, 2003). Moreover, Sahal (1981) and Bozeman (2000) emphasise that there is no clear distinction between knowledge transfer and technology transfer, since technology is always based on knowledge and this knowledge is always transferred in the moment when a technology is transferred between two organisations, such as a public research organisation and a firm.

There are numerous modes of KTT, both formal and informal. Formal KTT usually involves a legal instrument like a patent, license, or royalty agreement (Bozeman, 2000; Feldman et al., 2002; Thursby and Thursby, 2002). In contrast to this, informal KTT refers either to the absorption of knowledge codified in specific research outputs or to interactions between public scientists and industry personnel. In this sense, knowledge could flow for example by technical assistance or consulting (Grimpe and Fier, 2010), within collaborative research (Link et al., 2007) or through a temporary or permanent move from public research to industry (COM, 2006). We use the term KTT in a broad understanding that refers to knowledge embodied in technological artefacts, codified and non-codified knowledge, as well as knowledge that is co-produced in various forms, e.g. in collaborative projects.

From the perspective of an industrial firm, interaction with public science is attractive for several reasons. Firms tend to "underinvest" in the production of new knowledge and 
technology through research and development $(\mathrm{R} \& \mathrm{D})$ as the results achieved may be relevant for other companies and may thus spill over to competitors (Arrow, 1962). Further, knowledge production incurs high costs, as knowledge often involves complex and dynamic processes which firms cannot cope with internally (Dasgupta and David, 1994; Crespi et al., 2006). Firms therefore strive to get access to complementary resources in universities and public research organisations and to explore new technological opportunities (Jacobsson, 2002; Santor and Chakrabarti, 2002; Adams, 2006; Broström, 2010). Firms also need access to the public scientists themselves in order to hire scientific personnel and thus to keep up their absorptive capacity for future KTT activities (Hall et al., 2003), as knowledge sought through external experts is often complementary to firms' technological core (Song et al., 2003). Within the last few years, several studies have evaluated the links between science and industry with a view to firm success, typically finding that firms' ability to innovate is positively influenced by industry-science interaction (Arvanitis et al., 2008; Broström, 2010). Further exemplary evidence includes Belderbos et al. (2004) who examine industry-science interactions on the basis of a large scale innovation survey, concluding that interactions between firms and universities or research institutes significantly increase the firm's sales with innovative products. A study of German companies found that firms sourcing knowledge from universities are more likely to innovate (Edler, 2003).

While the generally positive effects of KTT on firm performance provide an explanation for why firms seek to collaborate with academics, existing literature has also shed light on what drives individual scientists to collaborate with firms and engage in KTT activities. This literature has developed within connected but slightly different conceptual lenses. A first lens is the resource-based view (e.g., van Rijnsover et al, 2007), which - in line with the original concept developed for firms (e.g., Barney, 1991) - posits that individuals are enabled to collaborate by the resources at their disposal. They seek collaboration to enhance these resources and thus improve their personal competitive advantage vis-à-vis other researchers. A second approach to look at individual determinants of KTT is to understand the organisational context, i.e. the characteristics of organisations that encourage, enable or constraint scientists in their KTT efforts (e.g., Meyer-Krahmer and Schmoch, 1998; Siegel et al., 2003; Siegel et al. 2004; Ponomariov and Boardman, 2010). A third and related approach is the scientific and technical human capital approach, which refers to scientific and technical human capital as "individual endowments", tacit and craft knowledge as well as social contacts and networks (e.g., Bozeman et al. 2001; Bozeman and Corley, 2004; Boardman, 2009; Ponomariov and Boardman, 2010). All approaches have in common that they focus on how various characteristics of individuals and their organisational environment influence their ability and inclination to engage with firms and transfer knowledge.

With respect to resource-driven considerations, scientists seek access to complementary knowledge, expertise and resources just like firms do (Katz and Martin, 1997; Melin, 2000; Thorsteinsdottir, 2000; Beaver, 2001). Link et al. (2007) examined knowledge transfer between academia and industry on the basis of a survey among university scientists. Their results suggest that university researchers rank collaboration with industry as very important because it allows them to benefit from the transferred knowledge and the use of equipment. Siegel et al. (2004) find that many researchers benefit from collaboration and knowledge 
transfer to industry due to the use of advanced equipment and laboratories at the firms' premises. Meyer-Krahmer and Schmoch (1998) investigated the importance of different types of interaction with industry. The interviewed scientists rated those interaction types with industry as more important that involved a bidirectional exchange of knowledge with industry, thus pointing towards the importance of both receiving and transferring knowledge. Moreover, scientists seek to collaborate with industry in order to get access to research grants as they have become a major source of university research funding (Beaver, 2001; Hall et al., 2003; Bozeman and Corley, 2004).

A second approach focuses on the meaning of the organisational environment. It has been shown that KTT differs depending on the mission and institutional context of public scientists. Broadly speaking, there is a substantial difference between university-affiliated scientists and those affiliated with institutionally funded basic research institutes on the one hand and scientists at public research institutes that are mission-oriented or that are set up to link science with industry on the other hand. For Germany, Schmoch et al. (2000) and Heinze and Kuhlmann (2008) have demonstrated that researchers at universities and Max Planck institutes, which are - by and large - more oriented towards basic research and publications as major indicator of excellence, tend to be less active in collaboration with firms than scientists from Fraunhofer institutes whose mission is application oriented and that need to acquire industry funding. This result has been confirmed by Ponomariov (2008) for universities, finding a negative correlation between scientific quality of university units and their propensity to collaborate with firms. Moreover, Ponomariov (2008) finds that the presence of industry near or on campus increases KTT activities.

Similarly, Siegel et al. (2004) show that a considerable number of scientists rate the reward systems for KTT at the research institutions as insufficient, thus obstructing a higher level of transfer activities. In fact, several papers have highlighted the importance of an appropriately designed reward system at the research institutions to stimulate the scientists' engagement in KTT. In this context, Friedman and Silberman (2003), Lach and Schankerman (2004) and Link and Scott (2005) find a positive relationship between royalty payments and the scientists' propensity to engage in KTT activities. Jensen et al. (2001), Owen-Smith and Powell (2001), and Thursby and Kemp (2002) highlight the critical role of intellectual property rights, such as patents, for KTT. They find that the faculty's awareness of commercialisation opportunities and an active involvement in the process of commercialisation of scientific discoveries positively influence the patenting behaviour of scientists. Patents, in turn, create opportunities to enter the "market for technology" and facilitate the exchange of knowledge assets (Arora et al., 2001). Finally, there is also clear evidence that scientists in different scientific fields have different collaboration behaviours (Meyer-Krahmer and Schmoch, 1998; Schmoch et al., 2000; Heinze and Kuhlmann, 2008).

Finally, the third approach, the scientific and technical human capital approach, puts emphasis on individual-level research capacity. It combines the first two lenses, but is slightly broader in discussing determinants of individual research capacity. Belkhodja and Landry (2007) show that a number of factors driving the scientist's scientific and technical human capital like the career age, productivity, hierarchical position as well as previous successful collaboration relate positively to the scale of collaboration with firms. Furthermore, scientists 
who are well connected, i.e. who occupy a central position in professional networks, collaborate significantly more. Boardman (2009) as well as Ponomariov and Boardman (2010) suggest that scientists affiliated with a university research centre may augment their scientific and technical human capital and, in this respect, their ability to conduct research together with industry and to publish the results. The underlying mechanism for this is the notion that social capital creates human capital. Joining a research centre implies interaction with other centre participants as well as access to centre resources. As a result, a scientist's centre-enhanced research capacity will facilitate industry-science interaction and KTT activities.

This review has demonstrated that scientists may engage in KTT for a variety of reasons. Although the three theoretical lenses presented - and particularly the resource-based view and the scientific and technical human capital approach - are interconnected, the following section will primarily draw from the scientific and technical human capital approach. This approach combines important perspectives of the other two approaches. However, it focuses on the influence that the broader environment and a whole range of factors related to the individual - such as career pathways, social position in networks (social capital) - have on the actor's resources and their application and hence on their behaviour. In short, a change in the broader environment or in those key factors can trigger a change in behaviour. For our study, this perspective best helps us to delineate the effects that international mobility of scientists - a feature of scientists' career paths that has become increasingly important - will likely have on engaging in KTT activities with firms both in the home and the host country.

\subsection{Linking KTT with international mobility of scientists}

Both KTT activities and scientist mobility have been characterised as increasingly important phenomena, and both promise benefits at the individual and systemic level. In this respect, it becomes imperative to explain the mechanism through which international mobility might have an impact on scientists' KTT activities. As indicated before, our theoretical reasoning will be guided by the scientific and technical human capital approach which has been applied in a number of recent studies investigating industry-science collaboration (e.g., Bozeman and Corley, 2004; Boardman, 2009; Ponomariov and Boardman, 2010). The scientific and technical human capital approach is particularly appropriate because of its emphasis on individual-level research capacity which can be affected - inter alia - by professional relationships and network ties. Our starting assumption is that international mobility might serve as a prominent way to increase an individual's embeddedness in professional academic and non-academic - networks which translates into higher scientific and technical human capital. Our overarching research hypothesis is therefore that international mobility of scientists increases the propensity that these scientists will engage in KTT activities to firms.

As our starting point, we identify two major dimensions of mobility that may have an influence on KTT activities of mobile scientists: the duration of a focal research visit to a host country institution, as well as the scientist's more general international orientation in her or his academic career, which we define as the frequency of research visits relative to the scientist's career age. Proponents of the scientific and technical human capital approach have 
argued that "social capital begets human capital" (Ponomariov and Boardman, 2010: 616). Mobile scientists are exposed to collaborators and probably resources they did not have access to before. In this respect, scientists increase their research capacity, i.e. their human capital, some of which might be the result of further training and development. Moreover, by making formal and informal connections, scientists also expand their social capital that eventually might increase their ability to facilitate the transfer of knowledge and technology to firms (Ponomariov and Boardman, 2010).

The duration of a research visit outside the scientist's home country may thus impact the scientific and technical human capital because longer research visits abroad result in more intensive experiences and stronger embeddedness in the foreign context. Such visits create opportunities for more intensive interaction and knowledge exchange or co-production of knowledge. While these arguments suggest that longer research visits abroad predominantly benefit KTT activities to firms in the host country, we might also expect positive effects of a longer visit for KTT activities to firms in the home country. The reason is that industry in the home country will typically have a higher interest in collaborating with a scientist with a higher scientific and technical human capital gained through international exposure. This opens the opportunity for firms to acquire more distant knowledge and technology with a high degree of novelty and uniqueness from the firm's point of view. Hence, our first hypothesis can be stated as:

Hypothesis 1a (H1a): The longer the research visit to an institution outside the scientist's home country takes, the higher the likelihood that the scientist will engage in KTT activities to firms in the home country.

Hypothesis $1 b$ (H1b): The longer the research visit to an institution outside the scientist's home country takes, the higher the likelihood that the scientist will engage in KTT activities to firms in the host country.

Second, the frequency of research visits abroad might have an important role to play as it reflects a form of the scientist's international orientation. Frequent research activities abroad may, for example, lead to a higher number of contacts, the build up of reputation and, therefore, also to a more diverse and broad potential for interactions. As before, a high frequency of visits also suggests that the scientist may become well embedded into the scientific context of the host country. This should particularly be true due to the cumulative effects of repeat visits as these are likely to better facilitate building up social capital. Moreover, we can assume that scientists with a high international orientation are generally more open-minded, which might also help in terms of establishing contacts with industry. As a consequence, a higher frequency of research visits abroad should facilitate KTT activities to firms both in the host and the home country.

Hypothesis 2a (H2a): The higher the frequency of research visits to institutions outside the scientist's home country, the higher the likelihood that the scientist will engage in KTT activities to firms in the home country. 
Hypothesis $2 b$ (H2b): The higher the frequency of research visits to institutions outside the scientist's home country, the higher the likelihood that the scientist will engage in KTT activities to firms in the host country.

Finally, it is of particular interest for policy makers to explore the relationship between KTT activities to firms in the host and the home country. If there was a positive correlation between KTT of a mobile scientist to firms in the host country and the home country, then international scientist mobility would have direct positive effects for firms in the home country, as well. Mobile and transfer-active scientists would constitute a natural transfer mechanism of relevant knowledge and technology to industry, regardless of national borders. In turn, the more mobile and transfer-active scientists a country had, the more attractive it would become as a location for international firms. In addition, a higher number of transfer active and mobile scientists would contribute to a more efficient and effective linking of complementary knowledge globally. Reflecting the brain drain discourse, there is an obvious imbalance between the growing need to foster mobility and KTT on the one hand, and concerns about a sufficient return of knowledge to the home country on the other hand. Both the scientific and technical human capital approach and the resource-based view would suggest that scientists prefer those transfer activities that promise a gain in knowledge for them as well, i.e. they seek reciprocal partnerships with firms, in order to expand their research capacities and human capital. If that is true, international KTT activities promise to yield positive effects on the scientists and thus will also benefit the innovation system of the scientist's home country. Moreover, scientists with collaborative experience can be assumed to be both more open to and more attractive for industrial partners as they understand the application-oriented interest of firms and know how to manage relationships with firms (Grimpe and Fier, 2010). If there are no confidentiality agreements between a scientist and a particular firm in place, scientists are therefore likely to seek further collaboration opportunities in order to acquire funding and to commercialise their knowledge and technology. As a result, our third hypothesis reads:

Hypothesis 3 (H3): There is a positive correlation between KTT activities to firms in the host and the home country.

In the following section we will outline our research methods used to test our hypotheses before we present the results.

\section{$3 \quad$ Research methods}

\subsection{Data}

The data used in our empirical analysis originate from a survey among German scientists carried out on behalf of the German Federal Ministry of Education and Research (Edler, 2007). The aim of the survey, which was part of a large-scale project on the internationalisation of German publicly financed research and science, was to depict the 
willingness, the motives and the actual extent of international mobility of scientists in Germany. Data were collected in 2006 using an online survey instrument.

An online survey is a particularly useful instrument in our case because it allowed us to reach those scientists who were temporarily absent from their home office, i.e. who were on a visit, in a quick and efficient way. In this respect, it can be regarded as superior compared to a survey administered via mail. Moreover, it enabled us to reach a large number of scientists who provided detailed information about their mobility pattern. While in-depth case studies with a selected group of scientists could have generated even more detailed information, they would have precluded further statistical analyses which allow us to draw conclusions based on a large number of observations and controlling for several individual and institutional factors. In any case, the information is self-reported, which could raise concerns with respect to response accuracy. However, we believe that the advantages of such an online survey outweigh the drawbacks (for a discussion see Bertrand and Mullainathan, 2001).

Two major data sources were used for the sampling procedure. In a first step, the population of scientists holding a $\mathrm{PhD}$ and employed at German universities was derived from the "Hochschullehrerverzeichnis" of the year 2005. The "Hochschullehrerverzeichnis" is a database containing the names, degrees and contact information of the academic personnel employed at German universities. ${ }^{7}$ In a second step, scientists at (partly) government-funded public research institutes were identified via an internet search of the institutes' websites. These research institutes belong to the four large German science organisations: Max Planck Society, Fraunhofer Society, Leibniz Association and Helmholtz Association. In total, around 20,000 scientists from 113 German universities and 231 research institutes were identified with their e-mail addresses and invited to participate in our survey. Questionnaires of 1,509 respondents were retained; the overall response rate was 15.8 percent, which can be regarded as satisfactory for such a large-scale online survey. ${ }^{8}$ For the analysis, we limited the sample to those scientific disciplines where a transfer of technological knowledge to firms is potentially relevant - i.e. in agricultural and environmental sciences; biology and chemistry; physics, mathematics and computer sciences; engineering sciences; medicine, psychology - thus excluding social sciences and humanities. Excluding cases with missing values leaves 958 observations available for analysis.

\subsection{Variables and measures}

\section{Dependent variable}

To qualify the KTT activities of scientists, the respondents were asked to indicate whether their most recent research activity outside of Germany resulted in a transfer of technological knowledge or expertise to a firm in Germany and/or in the host country. We chose the most recent visit as the focal visit of our analysis for several reasons. First of all, it could be argued that the most recent visit was actually not relevant at all. However, letting a scientist choose which visit to report from would probably heavily bias the results as scientists might only

This excludes the so-called "universities of applied sciences" whose major task is teaching and not research.

8 The response rate reflects the fact that many scientists could not be reached due to an outdated or misspelled e-mail address. 
choose those visits where KTT occurred. Defining the most relevant visit creates additional problems as scientists might have a different understanding of what they consider as relevant. Second, we can assume that scientists are better able to recall their experiences when reporting from the most recent visit compared to a visit that had taken place been a longer time ago. We hence obtain two dummy variables. However, only 54 percent of all scientists in our sample have international research experience. Whether KTT as a result of such activities occurred or not is therefore not observable for scientists lacking this experience. We will address this issue methodologically by estimating selection models (see the model section for details).

\section{Explanatory variables}

In order to capture the international mobility of scientists, we use two survey variables: the duration of the focal research visit, i.e. the scientist's most recent visit abroad, and the scientist's more general international orientation which we associate with the frequency of international visits.

International research activities can be limited in duration or indeterminate. The latter case might for example apply to German scientists with a regular working contract at an institution abroad. We therefore use four dummy variables for visits lasting between 1 to 3 months (short-term), 4 to 12 months (medium-term), longer than 12 months (long-term) and for research activities of indeterminate duration but at least for 12 months. The dummy for shortterm activities is used as the reference category in all regressions. It could be argued that the choice for the length of each category is somewhat arbitrary. However, we believe that a distinction between short-term, medium-term, long-term and research activities of indeterminate length abroad makes sense as they are also associated with different levels of effort for the scientist and corresponding administrative requirements. In this sense, shortterm stays of up to 3 months are relatively easy to realise as temporary accommodation and office space would be rather easy to find. Moreover, it may not be necessary to apply for a visa and deal with other bureaucratic issues. The U.S. Visa Waiver Program, for example, allows German citizens to stay for up to three months in the United States without a visa, as long as they do not take up employment. All these efforts can be assumed to increase with medium-term stays that take up to one year. If a research activity is planned that takes even longer, scientists will probably seek some form of permanent residency with consequences for private and administrative aspects of their lives. Hence, although such a four-level conceptualisation of duration is necessarily somewhat arbitrary, we believe that it represents a pragmatic approach to capture the scientist's mobility choice.

Our measure for the general international orientation of the scientist is defined as the number of research visits abroad that took longer than 1 month, divided by the scientist's career age. The career age is defined as the number of years that have passed since the scientist received her or his $\mathrm{PhD}$. For obvious reasons, the career age is closely connected to the scientist's opportunities to engage in research activities abroad. Hence, we use the career age to control for these age effects. The international orientation therefore shows the importance of research visits abroad during the scientist's career. 
Besides duration and frequency, we control for the destination of the scientist's research visit. In the questionnaire, scientists were asked to indicate the host country of their international research activities. These were grouped into three groups and we include dummy variables for Western Europe and North America. The rest of the world serves as the reference category. ${ }^{9}$

We have argued that the scientist's propensity to engage in KTT activities not only depends on mobility but also on other personal characteristics of the scientist. Therefore, we include several variables to control for the individual level effects. We measure the scientist's productivity by including dummy variables for her or his publication activities (i.e. 0 to 3, 4 to 6 , and more than 6 articles in refereed journals) and for having applied for a patent. These variables refer to the three years prior to the survey. We account for the age of the scientist by including the career age in linear and squared form to control for potential non-linearity. Moreover, we include dummy variables for the gender, whether the scientist is employed at a university or at one of the institutes belonging to the large German science organisations (i.e., Fraunhofer Society, Max Planck Society, Helmholtz Association, and Leibniz Association and other institutes, with the Leibniz and other institutes serving as reference group), and whether the scientist received a grant for the international research visit.

Further, we measure the enabling and pull factors of international research activities with two dummy variables. The first variable indicates enabling conditions. We asked whether the scientist perceived the available funding opportunities for international research activities to be sufficient. The second variable is the perceived importance of the research environment abroad relative to the home environment. We use two variables on the number of research groups or research institutions within Germany and outside of Germany which the scientist indicated to be important for her or his research (none, 1 to 4,5 to 10 , more than 10). When the number of important research groups abroad is higher than the number of domestic research groups, then the new variable takes on the value of 1 , if it is lower or the same, the value is 0 . Finally, we include discipline dummies (environmental sciences; biology, chemistry, pharmacy; engineering sciences; medicine, psychology), with physics, mathematics, computer sciences serving as a reference category in all estimations.

\subsection{Estimation model}

Our dependent variables, the transfer of knowledge and technology to firms in Germany or in the scientist's host country as a result of an international research visit, are only observable if scientists have international research experiences. All other scientists would consequently not be able to engage in such KTT. The sample is therefore censored, which implies that we have to use a two-stage selection model. Estimating a simple regression model using only data on scientists with international research experience (i.e. whether the scientist had been abroad for at least a month in her or his career at all) would generate inconsistent estimates

9 As the descriptive statistics will show, 85 percent of the scientists indicated North America and Western Europe as their destination. Despite a strong (politically motivated) interest in mobility to Asia and particularly China, it would thus not make sense to include separate dummy variables due to the low number of observations. 
(Heckman, 1979). Including international experience as an exogenous variable would ignore the endogeneity between the KTT behaviour and international experience. We address this issue by estimating probit models with selection correction. The models consist of estimating two equations. In the first stage, the selection equation stage, the probability for having international research experience at all is estimated. In the second stage, the regression of interest, the determinants of the KTT activities to firms in the host and the home country are investigated. The two stage selection model assumes that there is a potential correlation between the error terms of the two equations (see Greene, 1993, for a discussion). If that correlation is nonzero, estimates will be inconsistent unless accounted for through the selection model.

The Heckman selection model requires that at least one factor be identified that influences the selection (i.e. international experience), but not the dependent variable of the second stage regression model (i.e. KTT). We argue that the two variables portrayed as enabling and pull factors for international research activities fulfil this criterion. International research activities require funding, which will typically not be provided by the host institution. Therefore, scientists may apply for specific international grants or other grants. Moreover, research abroad only makes sense if there are opportunities to learn from and to collaborate with partners who work in similar fields and who provide an added value over domestic partners (pull). This does not imply that scientists will not go abroad if there are more potential domestic collaboration partners even though there are some research groups abroad which are highly important. However, we argue that a higher relative importance of international partners should at least result in a preference for international over domestic partners and thus increase the likelihood that international research activities occur. At the same time, both enabling and pull factors should not have any effect on the knowledge transfer behaviour of scientists. We test this assumption empirically by including the enabling and pull factors in both the first and second stage regression of a probit model with selection. As predicted, both variables have a positive and significant effect on the international experience and no significant effect on the KTT activities. Our estimation model can therefore be considered as valid.

In the second step of our estimation we employ a seemingly unrelated bivariate probit model. The model reflects our choice of two dummy variables as dependent variables: KTT to firms in the host and the home country. As outlined above, we are not only interested in the relation between the independent and the dependent variables, but also in the relation between the two dependent variables. We have argued that the two variables have a complementary relationship, i.e. KTT to firms in the host country does not substitute for knowledge transfer to firms in the home country and vice-versa. Instead, a complementary relationship would indicate that both directions of knowledge transfer occur at the same time. The bivariate probit model provides an indirect test for complementarity. The idea is to test for a positive correlation between the two practices conditional on a vector of covariates $X$ (Athey and Stern, 1998; Cassiman and Veugelers, 2006). If the resulting correlation coefficient rho is positive and significant we can assume that both practices are complements rather than substitutes. 


\section{$4 \quad$ Results}

\subsection{Basic characteristics of scientist mobility and KTT}

Table 1 shows the descriptive statistics of the dependent as well as our main explanatory and control variables. Correlation tables for the variables in the first and second stage of the selection models can be found in the appendix. There is no indication for collinearity in our data as evidenced by the low values of the variance inflation factors (VIF) and condition numbers (Belsley et al., 1980).

Table 1: Descriptive statistics - mobility of German scientists

\begin{tabular}{|c|c|c|c|c|c|}
\hline Variable & Obs. & Mean & Std. Dev. & Min. & Max. \\
\hline Transfer to firms in Germany (d) & 514 & 0.163 & 0.370 & 0 & 1 \\
\hline Transfer to firms in the host country (d) & 509 & 0.169 & 0.375 & 0 & 1 \\
\hline Short-term stay (1 to 3 months) (d) & 514 & 0.461 & 0.499 & 0 & 1 \\
\hline Medium-term stay (4 to 12 months) (d) & 514 & 0.138 & 0.345 & 0 & 1 \\
\hline Long-term stay (> 12 months) (d) & 514 & 0.171 & 0.377 & 0 & 1 \\
\hline Stay of indeterminate length (d) & 514 & 0.230 & 0.421 & 0 & 1 \\
\hline International orientation (ratio) & 514 & 0.290 & 0.246 & 0 & 1.111 \\
\hline Grant received for the focal research visit (d) & 514 & 0.796 & 0.404 & 0 & 1 \\
\hline Host country in Western Europe (d) & 514 & 0.259 & 0.438 & 0 & 1 \\
\hline Host country in North America (d) & 514 & 0.591 & 0.492 & 0 & 1 \\
\hline International experience of at least one month (d) & 958 & 0.537 & 0.499 & 0 & 1 \\
\hline Career age (years) & 958 & 15.437 & 10.283 & 0 & 41 \\
\hline Gender (d, 1=female) & 958 & 0.148 & 0.356 & 0 & 1 \\
\hline Employed at a university (d) & 958 & 0.467 & 0.499 & 0 & 1 \\
\hline Employed at Fraunhofer institute (d) & 958 & 0.068 & 0.252 & 0 & 1 \\
\hline Employed at Max Planck institute (d) & 958 & 0.134 & 0.340 & 0 & 1 \\
\hline Employed at Helmholtz institute (d) & 958 & 0.244 & 0.430 & 0 & 1 \\
\hline Employed at Leibniz or other institute (d) & 958 & 0.129 & 0.336 & 0 & 1 \\
\hline Patent application in last 3 years (d) & 958 & 0.310 & 0.463 & 0 & 1 \\
\hline No. of publications in last 3 years $0-3$ (d) & 958 & 0.267 & 0.443 & 0 & 1 \\
\hline No. of publications in last 3 years 4-6 (d) & 958 & 0.237 & 0.425 & 0 & 1 \\
\hline No. of publications in last 3 years $>6$ (d) & 958 & 0.486 & 0.500 & 0 & 1 \\
\hline Environmental sciences (d) & 958 & 0.144 & 0.351 & 0 & 1 \\
\hline Biology, chemistry, pharmacy (d) & 958 & 0.290 & 0.454 & 0 & 1 \\
\hline Physics, mathematics, computer science (d) & 958 & 0.310 & 0.463 & 0 & 1 \\
\hline Engineering sciences (d) & 958 & 0.119 & 0.324 & 0 & 1 \\
\hline Medicine, psychology (d) & 958 & 0.137 & 0.344 & 0 & 1 \\
\hline Satisfied with availability of funding for intern. mobility (d) & 958 & 0.211 & 0.408 & 0 & 1 \\
\hline Rel. imp. of research groups abroad higher than at home (d) & 958 & 0.693 & 0.461 & 0 & 1 \\
\hline
\end{tabular}

The descriptive statistics show that slightly more than half of the scientists in our sample do have international experience and can be used in the second stage of the selection model. The statistics further show that two dependent variables on the KTT behaviour are almost equally distributed. About one out of five scientists transferred knowledge and technology to firms in Germany during the focal research visit abroad. Slightly more scientists have engaged in KTT to firms abroad, i.e. in their (former) host countries.

Regarding the explanatory variables, our main focus is on the mobility variables. It turns out that, based on the information about their last research visit abroad, the majority of German academics go abroad for a rather short period of 1 to 3 months. Medium-term stays are 
somewhat less common (14 percent) than long-term stays (17 percent). Moreover, 23 percent of the scientists indicated their research activity abroad to be of indeterminate length. The international orientation, expressed by the ratio of the number of research visits and the career age, shows that on average scientists go abroad for at least one month about every fourth year. Most of the scientists chose North America as the destination for their international research activities and the vast majority received a grant for these activities.

The second group of explanatory variables reflects personal and professional characteristics of the scientists in our sample. On average, the scientists have been active after their $\mathrm{PhD}$ for 15 years (career age), and 15 percent of the scientists in the sample are female. Moreover, the descriptive statistics show that the sample is almost equally balanced regarding the locus of employment of the scientists (universities vs. non-universitary, i.e. public research institutes). Regarding the scientific productivity during the three years prior to the survey, it turns out that around 30 percent of the scientists had applied for at least one patent and most of the scientists had published more than 6 papers in refereed journals. With respect to the scientific discipline, about every third scientist in our sample is working in the fields of physics, mathematics or computer science. These disciplines are followed by biology, chemistry, pharmacy (29 percent), environmental sciences (14 percent), medicine, psychology (14 percent), and engineering sciences (12 percent).

The last two explanatory variables work as exclusion restrictions in the selection models, i.e. they are expected to determine the decision to be internationally mobile at all but they should be irrelevant for the decision to transfer knowledge and technology. Only 21 percent of the academics stated to be satisfied with the available funding opportunities for international research activities. The second exclusion restriction reflects the scientists' assessment of the importance of research groups abroad. Almost 70 percent of the scientists indicated the importance of foreign research groups to be higher than domestic research groups for their own research activities.

\subsection{International mobility as the determinant of KTT activities}

Table 2 shows the results from our probit selection models for the scientists' decision to move abroad (first stage of the model) and to engage in KTT activities either to firms in Germany or in the host country (second stage of the model). In the following, we will first discuss the results from the first stage before we move on to the second stage. We can see from the rho coefficient in the lower part of Table 2 that there is a significant correlation between the error terms of the two equations for the second model (KTT to firms in the host country). This indicates that a selection model is in fact required to yield consistent estimates results.

The enabling and pull factors - availability of funding and relative importance of scientists abroad - which serve as exclusion restrictions turn out to be significant in the two first stage equations and they have the expected sign. The propensity to move abroad for a period of at least one month increases when scientists are satisfied with the availability of funding for such activities and when they realise that research groups or institutions abroad are relatively more important than in the home country. 
Concerning the other explanatory variables of the decision to go abroad, our findings indicate that neither the career age nor the gender have an effect. The organisational context however, matters.. University scientists appear to be much more likely to go abroad compared to scientists at Fraunhofer or Helmholtz institutes. A reason for this is that many scientists at Fraunhofer and Helmholtz institutes are more likely to have permanent contracts, and they focus more on application-driven research, often in close collaboration with industry. Thus, they have lower pressure (or incentives) and less opportunities to become a visiting researcher abroad.

Moreover, our results reveal a link between going abroad and being highly productive in terms of publication output. Scientists with more than 6 publications achieved during a threeyear period prior to the survey (the reference group) are significantly more likely to go abroad than those with lower publication output. There are indications for a virtuous circle: highly credentialed scientists are more attractive as collaboration partners and thus more likely to be invited to or engaged in international research activities. At the same time, these excellencedriven research visits increase the likelihood for subsequent high level publications with international colleagues. In contrast, and in line with our observations of non-university staff, application-oriented research productivity (indicated in our survey by having previously applied for a patent) is not linked to mobility.

Regarding the scientific disciplines, scientists in environmental sciences, engineering sciences and medicine or psychology have a lower propensity to move abroad than the reference group which are scientists in physics, mathematics and computer science.

Table 2: Probit models with selection - determinants of the decision to go abroad (first stage) and to engage in KTT to firms (second stage)

\begin{tabular}{|c|c|c|c|c|}
\hline & \begin{tabular}{|c|}
$\begin{array}{c}\text { Decision to go } \\
\text { abroad }\end{array}$ \\
\end{tabular} & $\begin{array}{l}\text { KTT to firms } \\
\text { in Germany }\end{array}$ & \begin{tabular}{|c|}
$\begin{array}{c}\text { Decision to go } \\
\text { abroad }\end{array}$ \\
\end{tabular} & $\begin{array}{l}\text { KTT to firms } \\
\text { in host country }\end{array}$ \\
\hline Medium-term stay (4 to 12 months) (d) & & $\begin{array}{l}-0.306 \\
(0.247)\end{array}$ & & $\begin{array}{l}-0.207 \\
(0.197)\end{array}$ \\
\hline Long-term stay (>12 months) (d) & & $\begin{array}{c}0.620 * * * \\
(0.228)\end{array}$ & & $\begin{array}{l}0.497 * * \\
(0.214)\end{array}$ \\
\hline Stay of indeterminate length (d) & & $\begin{array}{c}0.214 \\
(0.254)\end{array}$ & & $\begin{array}{l}0.542^{* *} \\
(0.234)\end{array}$ \\
\hline International orientation (ratio) & & $\begin{array}{l}0.547^{*} \\
(0.325)\end{array}$ & & $\begin{array}{c}0.156 \\
(0.235)\end{array}$ \\
\hline Grant received (d) & & $\begin{array}{c}0.081 \\
(0.185)\end{array}$ & & $\begin{array}{c}-0.09 \\
(0.131)\end{array}$ \\
\hline Host country in Western Europe (d) & & $\begin{array}{l}-0.202 \\
(0.235)\end{array}$ & & $\begin{array}{c}-0.434^{* *} \\
(0.212)\end{array}$ \\
\hline Host country in North America (d) & & $\begin{array}{l}-0.298 \\
(0.220)\end{array}$ & & $\begin{array}{c}-0.403^{* *} \\
(0.186)\end{array}$ \\
\hline Career age (years) & $\begin{array}{l}-0.004 \\
(0.017)\end{array}$ & $\begin{array}{l}-0.027 \\
(0.033)\end{array}$ & $\begin{array}{l}-0.005 \\
(0.017)\end{array}$ & $\begin{array}{c}0.031 \\
(0.026)\end{array}$ \\
\hline Career age (years, squared) & $\begin{array}{c}0.000 \\
(0.000)\end{array}$ & $\begin{array}{c}0.001 \\
(0.001)\end{array}$ & $\begin{array}{c}0.000 \\
(0.000)\end{array}$ & $\begin{array}{l}-0.001 \\
(0.001)\end{array}$ \\
\hline Gender (d, 1=female) & $\begin{array}{l}-0.024 \\
(0.127)\end{array}$ & $\begin{array}{c}0.016 \\
(0.227)\end{array}$ & $\begin{array}{l}-0.003 \\
(0.126)\end{array}$ & $\begin{array}{c}-0.01 \\
(0.174)\end{array}$ \\
\hline Employed at university (d) & $\begin{array}{c}0.512 * * * \\
(0.120)\end{array}$ & $\begin{array}{c}0.034 \\
(0.274)\end{array}$ & $\begin{array}{c}0.470 * * * \\
(0.119)\end{array}$ & $\begin{array}{c}-0.344 * * \\
(0.163)\end{array}$ \\
\hline
\end{tabular}




\begin{tabular}{|c|c|c|c|c|}
\hline & \begin{tabular}{|c|}
$\begin{array}{c}\text { Decision to go } \\
\text { abroad }\end{array}$ \\
\end{tabular} & $\begin{array}{l}\text { KTT to firms } \\
\text { in Germany }\end{array}$ & \begin{tabular}{|c|}
$\begin{array}{c}\text { Decision to go } \\
\text { abroad }\end{array}$ \\
\end{tabular} & $\begin{array}{l}\text { KTT to firms } \\
\text { in host country }\end{array}$ \\
\hline Employed at Fraunhofer institute (d) & $\begin{array}{c}-0.582 * * * \\
(0.206)\end{array}$ & $\begin{array}{c}1.050 * * * \\
(0.356)\end{array}$ & $\begin{array}{c}-0.650 * * * \\
(0.207)\end{array}$ & $\begin{array}{c}0.917 * * * \\
(0.298)\end{array}$ \\
\hline Employed at Max Planck institute (d) & $\begin{array}{l}-0.121 \\
(0.158)\end{array}$ & $\begin{array}{l}-0.312 \\
(0.295)\end{array}$ & $\begin{array}{l}-0.178 \\
(0.160)\end{array}$ & $\begin{array}{l}-0.035 \\
(0.224)\end{array}$ \\
\hline Employed at Helmholtz institute (d) & $\begin{array}{c}-0.440^{* * *} \\
(0.134)\end{array}$ & $\begin{array}{c}0.059 \\
(0.286)\end{array}$ & $\begin{array}{c}-0.461 * * * \\
(0.133)\end{array}$ & $\begin{array}{c}0.295 \\
(0.202)\end{array}$ \\
\hline Patent application (d) & $\begin{array}{l}-0.057 \\
(0.103)\end{array}$ & $\begin{array}{c}0.587 * * * \\
(0.164)\end{array}$ & $\begin{array}{l}-0.071 \\
(0.103)\end{array}$ & $\begin{array}{l}0.310 * * \\
(0.144)\end{array}$ \\
\hline No. of publications in last 3 years $0-3$ (d) & $\begin{array}{c}-0.639 * * * \\
(0.112)\end{array}$ & $\begin{array}{c}0.332 \\
(0.294)\end{array}$ & $\begin{array}{c}-0.661^{* * *} \\
(0.112)\end{array}$ & $\begin{array}{c}0.437 * * \\
(0.198)\end{array}$ \\
\hline No. of publications in last 3 years 4-6 (d) & $\begin{array}{c}-0.257^{* *} \\
(0.112)\end{array}$ & $\begin{array}{c}0.148 \\
(0.197)\end{array}$ & $\begin{array}{c}-0.257^{* *} \\
(0.112)\end{array}$ & $\begin{array}{c}0.168 \\
(0.149)\end{array}$ \\
\hline Environmental sciences (d) & $\begin{array}{c}-0.361^{* *} \\
(0.144)\end{array}$ & $\begin{array}{l}-0.218 \\
(0.281)\end{array}$ & $\begin{array}{c}-0.389 * * * \\
(0.144)\end{array}$ & $\begin{array}{c}0.168 \\
(0.203)\end{array}$ \\
\hline Biology, chemistry, pharmacy (d) & $\begin{array}{l}-0.190 \\
(0.118)\end{array}$ & $\begin{array}{l}-0.263 \\
(0.217)\end{array}$ & $\begin{array}{l}-0.216^{*} \\
(0.119)\end{array}$ & $\begin{array}{c}0.025 \\
(0.166)\end{array}$ \\
\hline Engineering sciences (d) & $\begin{array}{c}-0.781^{* * *} \\
(0.158)\end{array}$ & $\begin{array}{c}0.716^{* *} \\
(0.353)\end{array}$ & $\begin{array}{c}-0.767 * * * \\
(0.157)\end{array}$ & $\begin{array}{c}0.796^{* * *} \\
(0.220)\end{array}$ \\
\hline Medicine, psychology (d) & $\begin{array}{c}-0.768 * * * \\
(0.145)\end{array}$ & $\begin{array}{c}0.307 \\
(0.336)\end{array}$ & $\begin{array}{c}-0.779 * * * \\
(0.145)\end{array}$ & $\begin{array}{c}0.374 \\
(0.252)\end{array}$ \\
\hline Availability of funding (d) & $\begin{array}{l}0.203^{*} \\
(0.109)\end{array}$ & & $\begin{array}{l}0.176 * \\
(0.102)\end{array}$ & \\
\hline Relative importance of scientists abroad (d) & $\begin{array}{c}0.259 * * * \\
(0.100)\end{array}$ & & $\begin{array}{c}0.265^{* * *} \\
(0.090)\end{array}$ & \\
\hline Constant & $\begin{array}{c}0.384^{*} \\
(0.223)\end{array}$ & $\begin{array}{c}-1.260^{* *} \\
(0.610)\end{array}$ & $\begin{array}{c}0.440 * * \\
(0.220)\end{array}$ & $\begin{array}{c}-0.646 \\
(0.446) \\
\end{array}$ \\
\hline Rho & $\begin{array}{c}-0.254 \\
(0.541)\end{array}$ & & $\begin{array}{c}-0.804^{*} \\
(0.204)\end{array}$ & \\
\hline N (uncensored observations) & $958(514)$ & & $953(509)$ & \\
\hline Wald Chi2 & 67.186 & & 88.099 & \\
\hline P-value & 0.000 & & 0.000 & \\
\hline
\end{tabular}

In the second stage, which explains the determinants of KTT activities, we find differentiated results for KTT to firms in the home and the host country. First of all, long-term visits beyond 12 months increase the likelihood that scientists engage in KTT activities to firms in general, both in the home and the host country, in comparison to short-term visits, our reference category. In contrast to this, medium-term stays do not show a significant effect. With respect to stays of indeterminate length, our results indicate a positive effect only for KTT activities to firms in the host country. By and large, these findings provide support for hypothesis 1a and hypothesis 1b. Apparently, scientists need to be embedded into the host country's research environment for a year or more to fully realise the benefits from higher social capital and to generate the opportunities that result in a transfer of knowledge and technology. What is more striking, however, is that this not only holds true for the transfer to firms in the host country but also relates back to firms in the home country. A longer visit abroad is therefore beneficial to the innovation system of the scientist's home country and not detrimental as the discourse on brain drain might suggest. There is an additional benefit for 
the host country if the scientist's stay is indeterminate in length but this does not imply that there is a negative effect on KTT activities to firms in the home country. Hence, longer research visits apparently lead to the creation of additional scientific and technical human capital that facilitates collaboration with firms both in the host and the home country.

This finding is further supported when we look at the general international orientation of the scientists (defined as the number of visits abroad divided by the scientist's career age). Here we find a positive and significant effect for KTT to firms in Germany, while there is no significant effect for a transfer to firms in the host country. This finding supports hypothesis 2a but rejects hypothesis 2b. Higher international orientation apparently leads to an increased attractiveness of the scientist for firms back in the home country (reputation, relevance), and it can be interpreted as an instrument for the creation of an international network that facilitates KTT opportunities. In short, frequent international mobility is conducive to KTT only in the home country. In contrast, for KTT to firms abroad it is not frequent international mobility but only the duration of the visits abroad which makes a difference. This confirms the need for embedding and building up trust as a precondition for KTT abroad.

We find no effect of the scientist's host country in the decision for KTT to firms in the home country. However, our results show strong negative effects in the decision for KTT to firms in the host country if the host country was in Western Europe or North America compared to the rest of the world. It seems that there is a split between the knowledge and excellence driven mobility to the U.S. and some advanced European countries that implies less proximity to application and industry on the one hand and more pull from other countries with a greater need for input to industrial R\&D from outside the country on the other hand. For those countries and the firms within them, mobility of scientists is one means to increase knowledge inflow into the country.

With respect to the other explanatory variables for the decision to engage in KTT, we find that grants supporting the international research activity do not have an effect, nor do the career age or gender play a role. Being employed at a university and having a high publication activity actually decrease the likelihood of KTT to firms in the host country, while there is no significant effect for KTT to firms in Germany. In other words, highly credentialed scientists with high academic output are less likely to transfer knowledge and technology to foreign firms. For those scientists, mobility is not linked to transfer activities abroad. In contrast, patents have a strong positive influence on the KTT activity in both models. The decisive connection between patent applications of scientists and their KTT activity, as pointed out by Schmoch et al. (2000) and Owen-Smith and Powell (2001), can thus be confirmed. This finding also indicates that scientific and technical human capital is characterised by a build up of skills and knowledge amenable to industrial application. Correspondingly, scientists at Fraunhofer institutes, which are by mission application and transfer oriented, are more likely to transfer knowledge and technology as opposed to their colleagues at universities (Heinze and Kuhlmann, 2008). Strikingly, the effect on KTT is highest for scientists at Fraunhofer institutes despite their low mobility. This combination of low mobility and high KTT activity contrasts sharply with university scientists who exhibit high mobility but low propensity for KTT and with scientists at Helmholtz institutes who exhibit both low mobility and a low propensity for KTT. Again, the organisational context appears to moderate the extent to which 
scientific and technical human capital can be developed. Differences also emerge with respect to the scientific disciplines. We find that engineers are much more likely to transfer knowledge and technology than scientists from any other field to firms in the home and host country. In fact, there is a strong tradition of industry-science collaboration in engineering sciences in Germany (Grimpe and Fier, 2010).

Finally, Table 3 shows the results from the bivariate probit model for the relationship between KTT activities to firms in Germany and, at the same time, to firms in the host country, i.e. between our two dependent variables. In this model we can only use the data on scientists who actually reported international experience, which explains the smaller sample size. It turns out that the rho correlation coefficient - conditional on the vector of covariates $X$ - is highly significant with a value of 0.858. Apparently, there is no trade-off between both transfer directions, but rather a mutually reinforcing, i.e. complementary, relationship. Scientists who transfer technology to firms in Germany do so also to firms in the host country. Transfer effects are thus distributed broadly and there is no clear home or host country advantage. Consequently, hypothesis 3 receives full support. As a caveat, our data do not allow us to investigate scientist behaviour over time, i.e. whether scientists started engaging in KTT activities in the host country and continued in the home country. 
Table 3: Bivariate probit model - determinants of the decision to engage in KTT to firms

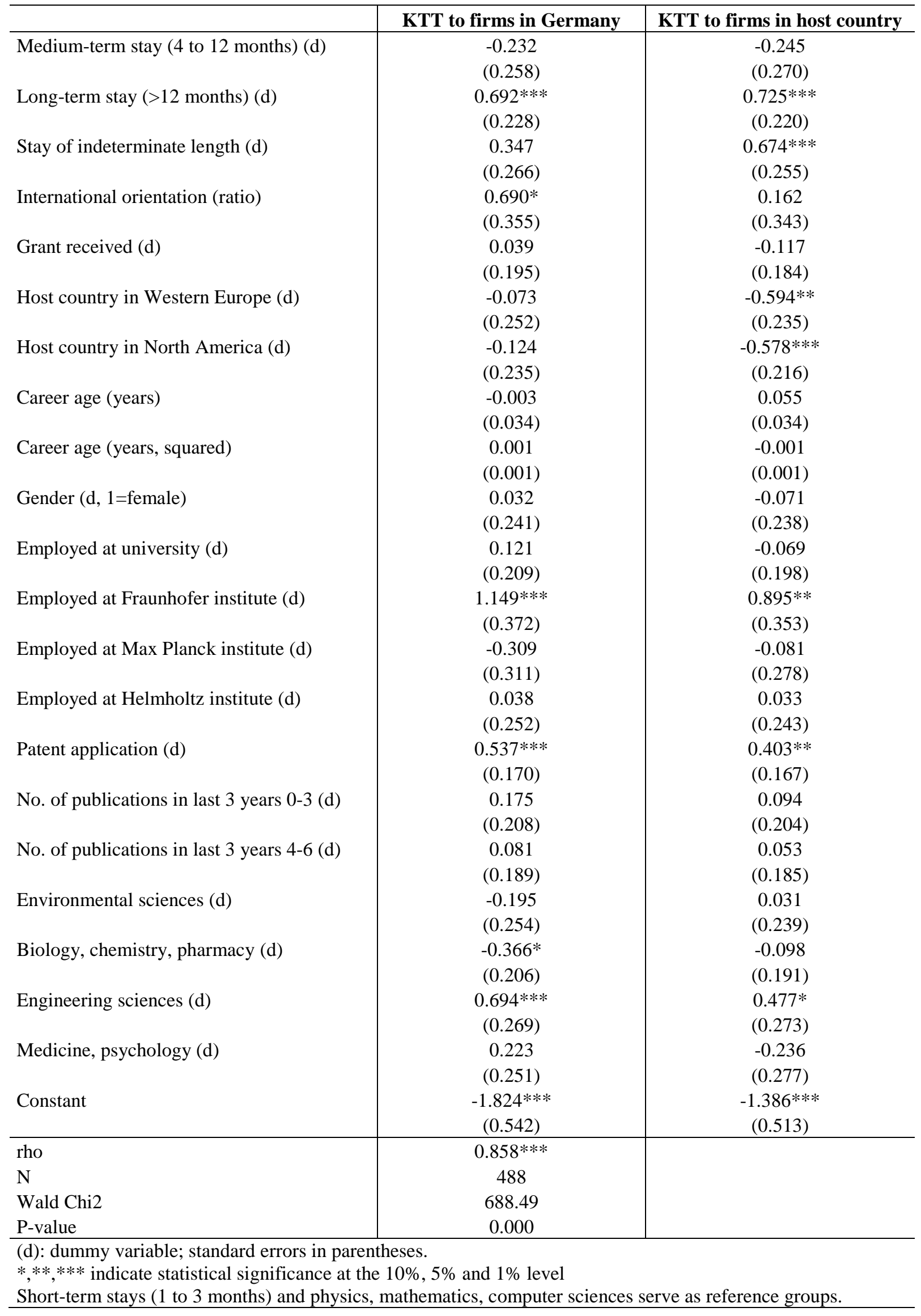




\section{$5 \quad$ Conclusion and policy implications}

Using a survey of more than 950 German scientists from universities and public research centres, this paper for the first time links the determinants and patterns of international mobility of scientists with their engagement in KTT activities. The findings confirm most of our hypotheses, qualify others, and bring to the fore a set of results that need deeper and more comparative research.

A first set of findings concerns the mobility patterns and conditions for mobility in general as a pre-condition for international KTT. More than 50 percent of the scientists have been abroad for at least a month during their career. We have found that mobile researchers are more productive in terms of publications. In this respect, mobility can be characterised as a consequence of as well as a catalyst for excellence. Moreover, in order to be mobile, 80 percent of the scientists indicated that their focal research visit had been funded at least partially through grants. At the same time, only one fifth of all scientists are satisfied with the support they can get for international mobility. The results further show that the existence of strong and important research groups abroad is an important pull factor for mobility. Given that excellence and relevance in scientific knowledge production are spreading across the globe with the emergence of new scientific strongholds, the opportunities and needs for international mobility can be assumed to increase accordingly.

Our analysis has produced a set of new insights as to the relationship between mobility and KTT. First of all, scientists who transfer knowledge and technology do so, generally speaking, both at home and abroad. In other words, there is a complementary relationship between both activities (confirming H3). This is important as knowledge accumulates continuously through KTT and subsequent KTT encompasses the knowledge of earlier transfers. Transferring knowledge abroad while being mobile thus does not diminish the activities and effects of subsequent transfers but rather increases them.

Second, the duration of research visits has a positive impact on the propensity to transfer knowledge and technology in the host country and in the home country (confirming H1a and H1b). While the simple transfer of artefacts or licenses can be achieved through short contacts, transferring complex and maybe even tacit technological knowledge requires more intensive contact over time. Third, and potentially more important, the more frequently scientists are internationally mobile during their career, the more they engage in KTT activities to firms in their home country (confirming H2a), while frequency does not have implications for the likelihood to engage in KTT in the host country (rejecting H2b). Hence, it apparently pays off for a country if its scientists are frequently abroad. Generally speaking, mobility can thus be characterised as a driver for the scientific and technical human capital that facilitates collaboration with industry. Fourth, the direction of mobility makes a difference for KTT abroad but not at home. Mobile German scientists are more inclined to engage in KTT to firms outside North America and Western Europe, while for KTT back home it is not important in which country the scientists had been.

Finally, the institutional context matters considerably in that it appears to interact with the creation of scientific and technical human capital. University scientists are much more likely 
to be mobile but less inclined to transfer knowledge and technology internationally than scientists from public research institutes. In this regard, we find that scientists at Fraunhofer institutes typically engage in KTT despite their low mobility which is in sharp contrast to university scientists who have a higher likelihood to go abroad but are less inclined to engage in KTT. Scientists at Helmholtz institutes also contrast sharply with Fraunhofer and university scientists as they exhibit a low likelihood both to go abroad and to engage in KTT.

Our findings contribute to the literature in several ways. We provide for the first time empirical evidence for the effects that international mobility has on KTT activities of academics. In this respect, we extend existing literature that has so far predominantly focused on permanent migration (e.g., Regets, 2007). Moreover, based on empirical evidence our research provides insights into the factors that, on the one hand, drive scientists to go abroad and, on the other hand, determine whether and where scientists engage in KTT. Form a theoretical perspective, we extend the application of the scientific and technical human capital approach by identifying mobility as a means to increase both the scientist's human and social capital that result from being embedded in an international network.

While these findings provide interesting insights, it is important to acknowledge the limitations of our research. Mobility is a multi-faceted construct while our approach only considers the most recent research visit that a scientist reports. In this regard, we do not account for the individual "history" of a scientist's research visits, for example repeat visits to the same host country institution. Moreover, we know little about the specific circumstances of the focal visit like the scientist's motivation and objectives. Our findings are also limited to the extent that KTT activities are measured using a dummy variable that does not account for the different modes or types of knowledge to be transferred. Consequently, these limitations have to be considered when it comes to the implications for STI policy.

As for policy and framework conditions, the main - and simplest - message is that international mobility needs to be enabled and actively supported as it is positively linked to excellence and KTT; it is beneficial in terms of enhancing scientific and technical human capital of scientists and their propensity to transfer knowledge. From the perspective of the home country, support mechanisms for outward mobility particularly pay off if they allow scientists to gain experience abroad, to broaden networks and to frequently establish ties internationally. This would call for enabling frequent research visits with the opportunity to return to the home country, for example through secondments that allow scientists to stay linked to their home organisation. Moreover, the findings indicate that the potential threats from a brain drain are limited, even if the scientists opt for a long-term research activity abroad. In this respect, supporting scientists at public non-university research institutes, who tend to be less mobile than university scientists, would be most effective. This is obviously most beneficial in systems with a large non-university public research sector. In Germany, for example, there has long been a discussion as to how sensible it is to support mobility of such non-university scientists that are often more application and industry oriented (Edler, 2007). The findings in this study provide evidence for the benefits of outward mobility also for this particular group of scientists. 
In order to benefit from inward mobility, it is most beneficial for the host country if scientists stay for a considerable time period. Embedding into the host country system takes time. KTT within a foreign innovation system typically does not take place on a short-term basis but requires the build-up of trust, networks and mutual recognition. From the perspective of the host countries of foreign scientists, this has important implications. Attracting foreign scientists should be linked to specific collaborative projects, as this increases the likelihood that firms in the host country benefit from KTT. In other words, brain gain in public science should be turned into brain embedding through direct and close collaboration if the local industry is intended to benefit. Further, policies should encourage "shuttle” mobility. Rather than supporting a one-off part time attraction, they should enable (repeated) circulation as this tends to increase the likelihood of mutual transfer (Ackers and Gill, 2008). In fact, in Europe STI policy at all levels has already been quite eager to provide framework conditions that allow public scientists to engage in international research activities and in KTT. ${ }^{10}$ The motivation to promote KTT and scientist mobility is similar: while the individual and social benefit of both is high, transaction costs impede a full realisation of the benefits. A re-examination of the effectiveness of these policy instruments and their interplay in the light of our findings seems therefore warranted.

Our findings indicate that international mobility is part of an opening process of public science that benefits the home economy in many ways and thus does not pose a threat but an opportunity. Mobility can be supported for the benefit of the scientist, her or his scientific and organisational environment and the national innovation system. However, to develop more appropriate framework conditions and support mechanism, future research should particularly try to develop a more nuanced understanding of both the scientists' mobility patterns and the different ways knowledge and technology transfer could occur. Moreover, we restricted our understanding of mobility to intra-sectoral mobility and neglected inter-sectoral mobility. The latter refers to mobility from public research to industry-funded research and has been shown to be an effective mechanism to transfer both codified and tacit knowledge (OECD, 2002). It is obvious that these two types of mobility could be better linked, e.g. by analysing the scale and scope of cross-border mobility from the public research system into firms. If we want to understand the contribution of public research to the globalisation of KTT activities, this gap needs to be closed.

10 European science and technology policy is characterised by an abundance of measures and initiatives to promote KTT, cooperation and mobility. Two European sources may suffice to illustrate this claim: first, the European Trendchart Database (www.proinno-europe.eu) that gives an overview of all science and technology policy initiatives within the EU countries; second, the ERAWATCH database that collects and analyses science and technology policy across Europe (http://cordis.europa.eu/erawatch/). 


\section{References}

Ackers, L. and B. Gill (2008), Moving People and Knowledge. Scientific Mobility in an Enlarging European Union, Cheltenham.

Adams, J.D. (1990), Fundamental Stocks of Knowledge and Productivity Growth, Journal of Political Economy 98, 673-702.

Adams, J.D. (2006), Learning, Internal Research, and Spillovers, Economics of Innovation and New Technology, 15, 5-36.

Adams, W. (1968), Introduction, in: Adams, W. (ed.) The Brain Drain, New York.

Arora, A., A. Fosfuri and A. Gambardella (2001), Markets for Technology: The Economics of Innovation and Corporate Strategy, Cambridge, MA.

Arrow, K.J. (1962), Economic Welfare and the Allocation of Resources for Invention, in: Nelson, R. R. (ed.) The Rate and Direction of Inventive Activity: Economic and Social Factors, Princeton, NJ, 609-625.

Arvanitis, S., N. Sydow and M. Woerter (2008), Do specific forms of university-industry knowledge transfer have different impacts on the performance of private enterprises? An empirical analysis based on Swiss data, Journal of Technology Transfer, 33, 504533.

Athey, S. and S. Stern (1998), An Empirical Framework for Testing Theories About Complementarity in Organizational Design, NBER Working Paper No. 6600, Boston.

Barney, J.B. (1991), Firm Resources and Sustained Competitive Advantage, Journal of Management 17, 99-120.

Beaver, D. (2001), Reflections on Scientific Collaboration (and its Study): Past, Present and Future, Scientometrics 52, 365-377.

Bekhradnia, B. and T. Sastry (2005), Migration of Academic Staff to and from the UK, Higher Education Policy Institute (HEPI), London.

Belderbos, R., M. Carree and B. Lokshin (2004), Cooperative R\&D and Firm Performance, Research Policy 33, 1477-1492.

Belkhodja, O., and R. Landry (2007), The Triple-Helix Collaboration: Why Do Researchers Collaborate with Industry and the Government? What are the Factors that Influence the Perceived Barriers? Scientometrics, 70 (2): 301-332.

Belsley, D.A., E. Kuh and R.E. Welsh (1980), Regression Diagnostics: Identifying Influential Data and Sources of Collinearity, New York.

Bertrand, M. and S. Mullainathan (2001), Do People Mean What They Say? Implications for Subjective Survey Data, American Economic Review 91 (2), 67-72.

Boardman, P.C. (2009), Government Centrality to University-Industry Interactions: University Research Centers and the Industry Involvement of Academic Researchers, Research Policy 38, 1505-1516.

Bozeman, B. (2000), Technology Transfer and Public Policy: A Review of Research and Theory, Research Policy 29, 627-655.

Bozeman, B. and E. Corley (2004), Scientists' Collaboration Strategies: Implications for Scientific and Technical Human Capital, Research Policy 33, 599-616.

Bozeman, B., Dietz, J. and M. Gaughan (2001), Scientific and Technical Human Capital: An Alternative Model for Research Evaluation, International Journal of Technology Management 22, 636-655.

Broström, A. (2010), Firms' Rationales for Interaction with Research Universities and the Principles for Public Co-Funding, Journal of Technology Transfer, forthcoming. 
Casey, T., S. Mahroum, K. Ducatel and R. Barré (2001), The Mobility of Academic Researchers: Academic Careers and Recruitment in ICT and Biotechnology, European Commission: Joint Research Centre (DG JRC), EUR 19905EN.

Cassiman, B. and R. Veugelers (2006), In Search of Complementarity in the Innovation Strategy: Internal R\&D and External Knowledge Acquisition, Management Science 52 (1), 68-82.

Cervantes, M. and D. Guellec (2002), The Brain Drain: Old Myths, New Realities, http://www.oecdobserver.org/news/fullstory.php/aid/673/The_brain_drain:_Old_myth s,_new_realities.html.

COM (2005), A Mobility Strategy for the European Research Area; Researchers in the ERA: One Profession, Multiple Careers, Commission of the European Communities staff working document: Implementation Report 2004, SEC(2005) 474.

COM (2006), Mobility of Researchers between University and Industry. Report of an Expert Group, EUR 22573, Brussels.

Cox, D. and A. Verbeek (2008), Evidence on the Main Fators Inhibiting Mobility and Career Development of Researchers, Report for the European Commission, Brussels.

Crespi, G.A., A. Geuna and B. Verspagen (2006), University IPRs and Knowledge Transfer. Is the IPR Ownership Model More Efficient?, SEWPS (SPRU Electronic Working Paper Series) No. 154, Brighton.

Cummings, J.L. and B.-S. Teng (2003), Transferring R\&D Knowledge: The Key Factors Affecting Knowledge Transfer Success, Journal of Engineering and Technology Management 20, 39-68.

Dasgupta, P. and P. David (1994), Towards a New Economics of Science, Research Policy 3, 487-521.

Defazio, D., A. Lockett and M. Wright (2009), Funding Incentives, Collaborative Dynamics and Scientific Productivity: Evidence from the EU Framework Program, Resarch Policy 38, 293-305.

De Grip, A., D. Fourage and J. Saubermann (2010), What Affects International Migration of European Science and Engineering Graduates? Economics of Innovation and New Technology, 407-421.

Edler, J. (2003), The Management of Knowledge in German Industry, in: Foray, D. and F. Gould (eds.), Knowledge Management Practices in the Private Sector: An International Survey, Ottawa/Paris, 89-118.

Edler, J. ed. (2007), Internationalisierung der Deutschen Forschungs- und Wissenschaftslandschaft (Internationalisation of German Research and Science), Karlsruhe.

Feldman, M.P., I. Feller, J. Bercovitz and R. Burton (2002), Equity and the Technology Transfer Strategies of American Research Universities, Management Science 48, 105121.

Fiani, R. (2003), The Brain Drain: An Unmitigated Blessing, Centro Studii Luca d'Agliano Development Studies Working Paper 173.

Freeman, R., B. (2010), Gobalization of Scientific and Engineering Talent: International Mobility of Students, Workers, and Ideas and the World Economy, Economics of Innovation and New Technology, 19 (5), 398-406.

Friedman, J. and J. Silberman (2003), University Technology Transfer: Do Incentives, Management, and Location Matter? Journal of Technology Transfer 28, 17-30.

Gibbons, M., C. Limoges, H. Nowotny, S. Schwartzman, P. Scott and M. Trow (1994), The New Production of Knowledge: The Dynamics of Science and Research in Contemporary Societies, London.

Greene, W.H. (1993), Econometric Analysis, New York. 
Grimpe, C. and H. Fier (2010), Informal University Technology Transfer: A Comparison between the United States and Germany, Journal of Technology Transfer 35, 637-650.

Hall, B.H., A.N. Link and J.T. Scott (2003), Universities as Research Partners, Journal of Economic Studies 85, 485-491.

Heckman, J.J. (1979), Sample Selection Bias as a Specification Error, Econometrica 47 (1), 153-161.

HEFCE (2006), The Higher Education Workforce in England. A Framework for the Future, Higher Education Funding Council for England Issues Paper No. July 2006 / 21, London.

Heinze, T. and S. Kuhlmann (2008), Across Institutional Boundaries? Research Collaboration in German Public Sector Nanoscience, Resarch Policy 37 (5), 888-899.

Hunter, R. S., A. J. Oswald, and B. G. Charlton (2009), The Elite Brain Drain, The Economic Journal, 119(538): F231-F251.

Jaffe, A. (1989), The Real Effects of Academic Research, American Economic Review 97 (5), 957-970.

Jensen, R.A. and M.C. Thursby (2001), Proofs and Prototypes for Sale: The Licensing of University Inventions, American Economic Review 91, 240-259.

Jacobsson, S. (2002), Universities and Industrial Transformation: An Interpretative and Selective Literature Study with Special Emphasis on Sweden. Science \& Public Policy, 29, 345-365.

Katz, J.S. and B.R. Martin (1997), What is Research Collaboration? Research Policy 26, 1-18.

Lach, S. and M. Schankerman (2004), Royalty Sharing and Technology Licensing in Universities, Journal of the European Economic Association 2, 252-264.

Link, A.N. and J.T. Scott (2005), Universities as Partners in U.S. Research Joint Ventures, Research Policy 34, 385-393.

Link, A.N., D.S. Siegel and B. Bozeman (2007), An Empirical Analysis of the Propensity of Academics to Engage in Informal University Technology Transfer, Industrial \& Corporate Change 16 (4), 641-655.

Mansfield, E. (1991), Academic Research and Industrial Innovation, Research Policy 20 (1), $1-12$.

Melin, G. (2000), Pragmatism and Self-Organization: Research Collaboration on the Individual Level, Research Policy 29, 31-40.

Meyer-Krahmer, F. and U. Schmoch (1998), Science-Based Technologies: UniversityIndustry Interactions in Four Fields, Resarch Policy 27, 835-851.

Minbaeva, D., T. Pedersen, I. Bjorkman, C. Fey and H. Park (2003), MNC Knowledge Transfer, Subsidiary Absorptive Capacity and Knowledge Transfer, Journal of International Business Studies 34 (6), 586-599.

Mountford, A. (1997), Can a Brain Drain Be Good for Growth in the Source Economy? Journal of Development Economics 53 (2), 287-303.

Nguyen, C.H. (2006), Brain Drain or Brain Gain? The Revitalization of a Slow Death, http://www.usca.edu/essays/vol162006/chi.pdf.

OECD (2002), International Mobility of the Highly-Skilled, Policy Brief, Paris.

OECD (2007), The OECD Stan Indicators Database, Paris.

Owen-Smith, J. and W.W. Powell (2001), To Patent or Not: Faculty Decisions and Institutional Success at Technology Transfer, Journal of Technology Transfer 26, 99114.

Ponomariov, B.L. (2008), Effects of University Characteristics on Scientists' Interactions with the Private Sector: An Exploratory Assessment, Journal of Technology Transfer 33, 485-503. 
Ponomariov, B.L. and P.C. Boardman (2010), Influencing Scientists' Collaboration and Productivity Patterns through New Institutions: University Research Centers and Scientific and Technical Human Capital, Research Policy 39, 613-624.

Regets, M. (2007), Brain Circulation: The Complex National Effects of High-Skilled Migration, Presentation at the OECD Committee for Scientific and Technology Policy (CSTP) and Steering and Funding of Research Institutions (SFRI) Workshop on the International Mobility of Researchers, Paris, March 28, 2007.

Robinson, S., A. Mentrup, F. Barjak and M. Thelwall (2007), Collection and Analysis of Existing Data on Researchers Careers (Rescar) and Implementation of New Data Collection Activities, Final Report. EU Contract No. 150176-2005-Fisc-Be, Brussels.

Rothaermel, F.T., S.D. Agung and L. Jiang (2007), University Entrepreneurship: A Taxonomy of the Literature, Industrial \& Corporate Change 16 (4), 691-791.

Sahal, D. (1981), Alternative Conceptions of Technology, Resarch Policy 10, 2-24.

Salt, J. (1997), International Movements of the Highly-Skilled, OECD NEIM Division Occasional Paper No. 3, Paris.

Salter, A. and B. Martin (2001), The Economic Benefits of Publicly Funded Basic Research: A Critical Review, Resarch Policy 30 (3), 509-532.

Santoro, M. D. and A. K. Chakrabarti (2002). Firm Size and Technology Centrality in Industry-University Interactions. Research Policy 31, 1163-1180.

Saxenian, A. (2002), Brain Circulation: How High-Skilled Immigration Makes Everyone Better Off, Brookings Review 20 (1), 28-31.

Schiff, M. (2005), Brain Gain: Claims about its Size and Impact on Welfare and Growth are Greatly Exaggerated, IZA Discussion Paper No. 1599.

Schmoch, U., G. Licht and M. Reinhard eds. (2000), Wissens- und Technologietransfer in Deutschland, Stuttgart.

Siegel, D.S. and P. Phan (2005), Analyzing the Effectiveness of University Technology Transfer: Implications for Entrepreneurship Education, in: Liebcap, G. (ed.) Advances in the Study of Entrepreneurship, Innovation, and Economic Growth, Amsterdam, 138.

Siegel, D.S., D. Waldman and A.N. Link (2003), Assessing the Impact of Organizational Practices on the Relative Productivity of University Technology Transfer Offices: An Exploratory Study, Research Policy 32, 27-48.

Siegel, D.S., D.A. Waldman, L.E. Atwater and A.N. Link (2004), Toward a Model of the Effective Transfer of Scientific Knowledge from Academicians to Practitioners: Qualitative Evidence from the Commercialization of University Technologies, Journal of Engineering and Technology Management 21, 115-142.

Song, J., P. Almeida and G. Wu (2003), Learning-by-Hiring: When Is Mobility More Likely to Facilitate Interfirm Knowledge Transfer? Management Science 49 (4), 351-365.

Thorn, K. and L.B. Holm-Nielsen (2006), International Mobility of Researchers and Scientists: Policy Options for Turning a Drain into a Gain, UNU World Institute for Development Economics Research (UNU-WIDER), Research paper series 2006/83.

Thorsteinsdottir, O. (2000), External Research Collaboration in Two Small Science Systems, Scientometrics 49, 145-160.

Thursby, J.G. and S. Kemp (2002), Growth and Productive Efficiency of University Intellectual Property Licensing, Research Policy 31, 109-124.

Thursby, J.G. and M.C. Thursby (2002), Who Is Selling the Ivory Tower? Sources of Growth in University Licensing, Management Science 48, 90-104.

van Rijnsoever, F.J., L.K. Hessels and R.L.J. Vandeberg (2008). A Resource-Based View on the Interactions of University Researchers, Research Policy 37, 1255-1266. 


\section{Appendix}

Table 4: Correlation matrix (first stage of the selection model)

\begin{tabular}{|c|c|c|c|c|c|c|c|c|c|c|c|c|c|c|c|}
\hline & 1. & 2. & 3. & 4. & 5. & 6. & 7. & 8. & 9. & 10. & 11. & 12. & 13. & 14. & 15. \\
\hline 1. Availability of funding (d) & 1.00 & & & & & & & & & & & & & & \\
\hline 2. Relative importance of scientists abroad (d) & 0.02 & 1.00 & & & & & & & & & & & & & \\
\hline 3. Career age (years) & 0.03 & -0.14 & 1.00 & & & & & & & & & & & & \\
\hline 4. Gender (d) & -0.04 & 0.02 & -0.22 & 1.00 & & & & & & & & & & & \\
\hline 5. Employed at university (d) & 0.03 & -0.03 & 0.08 & -0.04 & 1.00 & & & & & & & & & & \\
\hline 6. Employed at Fraunhofer institute (d) & 0.01 & -0.10 & -0.03 & -0.09 & -0.17 & 1.00 & & & & & & & & & \\
\hline 7. Employed at Max Planck institute (d) & 0.02 & 0.11 & -0.08 & 0.02 & -0.29 & -0.11 & 1.00 & & & & & & & & \\
\hline 8. Employed at Helmholtz institute (d) & -0.03 & 0.03 & -0.04 & 0.07 & -0.44 & -0.15 & -0.22 & 1.00 & & & & & & & \\
\hline 9. Patent application (d) & -0.01 & -0.12 & 0.16 & -0.12 & -0.07 & 0.21 & -0.10 & 0.02 & 1.00 & & & & & & \\
\hline 10. Number of publications $0-3$ (d) & -0.02 & -0.05 & -0.10 & 0.05 & -0.13 & 0.13 & -0.04 & 0.05 & -0.03 & 1.00 & & & & & \\
\hline 11. Number of publications 4-6 (d) & -0.05 & 0.02 & -0.11 & 0.05 & -0.07 & 0.04 & -0.03 & 0.08 & -0.03 & -0.34 & 1.00 & & & & \\
\hline 12. Environmental sciences (d) & 0.03 & -0.07 & 0.03 & 0.03 & -0.06 & -0.08 & -0.10 & -0.01 & -0.13 & -0.01 & 0.05 & 1.00 & & & \\
\hline 13. Biology, chemistry, pharmacy (d) & -0.04 & 0.06 & -0.11 & 0.10 & -0.08 & -0.06 & 0.11 & -0.02 & 0.12 & -0.07 & -0.02 & -0.26 & 1.00 & & \\
\hline 14. Engineering sciences (d) & 0.02 & 0.01 & 0.06 & -0.08 & -0.04 & 0.06 & 0.09 & 0.08 & -0.15 & 0.01 & 0.00 & -0.28 & -0.43 & 1.00 & \\
\hline 15. Medicine, psychology (d) & -0.03 & -0.06 & 0.04 & -0.13 & 0.03 & 0.17 & -0.12 & 0.04 & 0.24 & 0.11 & 0.05 & -0.15 & -0.24 & -0.25 & 1.00 \\
\hline Variance inflation factor (VIF) & 1.01 & 1.06 & 1.15 & 1.10 & 1.95 & 1.36 & 1.57 & 1.81 & 1.23 & 1.26 & 1.22 & 1.85 & 2.33 & 2.41 & 1.83 \\
\hline Condition number & 12.56 & & & & & & & & & & & & & & \\
\hline
\end{tabular}


Table 5: Correlation matrix (second stage of the selection model)

\begin{tabular}{|c|c|c|c|c|c|c|c|c|c|c|c|c|c|c|c|c|c|c|c|c|}
\hline & 1. & 2. & 3. & 4. & 5. & 6. & 7. & 8. & 9. & 10. & 11. & 12. & 13. & 14. & 15 & 16. & 17. & 18. & 19. & 20. \\
\hline 1. Medium-term stay (d) & 1.00 & & & & & & & & & & & & & & & & & & & \\
\hline 2. Long-term stay (d) & -0.18 & 1.00 & & & & & & & & & & & & & & & & & & \\
\hline 3. Stay of indeterminate length (d) & -0.22 & -0.25 & 1.00 & & & & & & & & & & & & & & & & & \\
\hline 4. International orientation (ratio) & -0.04 & -0.15 & 0.11 & 1.00 & & & & & & & & & & & & & & & & \\
\hline 5. Grant received (d) & 0.05 & 0.00 & -0.16 & 0.09 & 1.00 & & & & & & & & & & & & & & & \\
\hline 6. Host country in Western Europe (d) & 0.07 & -0.02 & -0.03 & 0.08 & -0.02 & 1.00 & & & & & & & & & & & & & & \\
\hline 7. Host country in North America (d) & 0.00 & 0.08 & 0.15 & -0.08 & -0.04 & -0.71 & 1.00 & & & & & & & & & & & & & \\
\hline 8. Career age (years) & 0.08 & -0.13 & -0.46 & -0.30 & 0.02 & -0.04 & -0.14 & 1.00 & & & & & & & & & & & & \\
\hline 9. Gender (d) & -0.06 & 0.02 & 0.15 & 0.09 & -0.12 & 0.03 & 0.04 & -0.25 & 1.00 & & & & & & & & & & & \\
\hline 10. Employed at university (d) & -0.01 & -0.11 & 0.22 & 0.02 & -0.04 & -0.09 & 0.13 & -0.05 & 0.01 & 1.00 & & & & & & & & & & \\
\hline 11. Employed at Fraunhofer institute (d) & -0.01 & -0.08 & -0.08 & 0.06 & 0.01 & 0.06 & -0.05 & 0.05 & -0.04 & -0.11 & 1.00 & & & & & & & & & \\
\hline 12. Employed at Max Planck institute (d) & -0.03 & 0.21 & -0.15 & 0.03 & -0.06 & 0.00 & 0.01 & 0.01 & 0.00 & -0.37 & -0.07 & 1.00 & & & & & & & & \\
\hline 13. Employed at Helmholtz institute (d) & 0.08 & 0.02 & -0.21 & -0.04 & 0.02 & 0.01 & -0.01 & 0.12 & 0.01 & -0.39 & -0.08 & -0.18 & 1.00 & & & & & & & \\
\hline 14. Patent application (d) & 0.00 & 0.01 & -0.07 & -0.13 & -0.02 & -0.08 & 0.08 & 0.15 & -0.12 & -0.03 & 0.18 & -0.07 & 0.00 & 1.00 & & & & & & \\
\hline 15. No. of publications $0-3$ (d) & -0.06 & 0.04 & 0.10 & -0.02 & 0.00 & 0.07 & 0.00 & -0.16 & 0.13 & -0.07 & 0.03 & -0.02 & 0.00 & -0.03 & 1.00 & & & & & \\
\hline 16. No. of publications 4-6 (d) & 0.02 & -0.04 & 0.06 & 0.02 & 0.04 & -0.02 & 0.02 & -0.08 & 0.05 & -0.03 & 0.03 & -0.06 & 0.09 & -0.02 & -0.24 & 1.00 & & & & \\
\hline 17. Environmental sciences (d) & -0.05 & -0.02 & -0.06 & 0.10 & 0.05 & 0.03 & -0.21 & 0.03 & 0.00 & -0.01 & -0.04 & -0.11 & -0.01 & -0.12 & -0.02 & 0.02 & 1.00 & & & \\
\hline 18. Biology, chemistry, pharmacy (d) & -0.07 & 0.18 & 0.06 & -0.04 & 0.01 & -0.02 & 0.07 & -0.13 & 0.08 & -0.02 & -0.08 & 0.08 & -0.10 & 0.11 & -0.03 & -0.03 & -0.27 & 1.00 & & \\
\hline 19. Engineering sciences (d) & 0.03 & -0.13 & -0.04 & 0.03 & -0.04 & 0.05 & 0.01 & 0.11 & -0.08 & -0.10 & 0.04 & 0.15 & 0.13 & -0.16 & 0.00 & 0.01 & -0.30 & -0.51 & 1.00 & \\
\hline 20. Medicine, psychology (d) & 0.09 & -0.06 & -0.13 & -0.04 & 0.00 & 0.00 & -0.04 & 0.09 & -0.09 & -0.01 & 0.12 & -0.11 & 0.13 & 0.21 & 0.04 & 0.04 & -0.11 & -0.18 & -0.20 & 1.00 \\
\hline Variance inflation factor (VIF) & 1.19 & 1.44 & 1.84 & 1.24 & 1.08 & 2.26 & 2.46 & 1,75 & 1.13 & 1.73 & 1.17 & 1.60 & 1.60 & 1.18 & 1.16 & 1.12 & 2.11 & 2.65 & 2.94 & 1.63 \\
\hline Condition number & 18.73 & & & & & & & & & & & & & & & & & & & \\
\hline
\end{tabular}

